\section{Pain: there is a lot of it}

\author{
Phil Wiffen
}

A few weeks ago in October, the International Association for the Study of Pain (IASP) ${ }^{1}$ announced an initiative for a global year against pain.

Professor Dr Hans Georg Kress (Vienna), President of the European Federation of IASP Chapters stated that:

\begin{abstract}
One in five Europeans suffers from pain that has been occurring regularly for three months or longer; one in eleven, suffers from pain daily. There are 100 million people affected by chronic pain in the $27 \mathrm{EU}$ Members. Across the EU chronic pain accounts for nearly 500 million lost working days every year - costing the European economy around $€ 34$ billion.
\end{abstract}

This initiative presents a significant opportunity for hospital pharmacists to get involved and make a difference.

Many of these patients will present with other symptoms and their pain, though significant, may be incidental to their presentation. In some cases pain may be directly related to the main condition such as HIV neuropathy or diabetic neuropathy. In others they may have nerve damage from some other cause or even an unknown cause. Pharmacists need to

Correspondence to Phil Wiffen, Pain Research Unit, Churchill Hospital, Old Road, Oxford OX3 7LE, UK; phil.wiffen@ndcn.ox.ac.uk accept that pain is exactly what the patient says that it is. To take a view that a patient is not telling the truth about their pain is unacceptable.

The evidence for effective analgesics in acute pain is good. A recent Cochrane overview that I coauthored summarises 35 systematic reviews and is a good basis for decision making. ${ }^{2}$

Neuropathic pain is much more difficult to manage. The IASP definition is 'Pain caused by a lesion or disease of the somatosensory nervous system'. Generally this is due to either physical damage to nerves or to a disease process. Typically the pain is of a different nature often described with terms such as stabbing, burning, throbbing etc. Patients can also experience pain to what would normally be considered non-painful stimuli such as light touch. Although sometimes responding to conventional analgesics it is much more likely to respond to so called adjuvants such as antiepileptics and antidepressants. There is good evidence for gabapentin and pregabalin; there is also good evidence that lamotrigine is largely ineffective. For antidepressants, the tricyclics are the most tested, with some indication of effect mostly from small studies. The numbers needed to treat are generally around five and the general advice is to try one and titrate to either effect or intolerable adverse effects. If these agents are used, the onset of effect is usually faster than typically seen with antidepressants when treating depression and normally within a few days. It is worth changing to another drug in the same class when effect is not achieved or adverse effects are unacceptable. Many patients with neuropathic pain are willing to accept less than complete pain relief, although clearly that is desirable. For some, even a $10 \%$ reduction in their pain may make life more bearable.

Opioids are more controversial. There is a case for the use of these drugs but a good deal of resistance from prescribers. For patients who do not get relief from any other medicines they may be appropriate. The same principles of titration apply; titrate slowly until either effect or unacceptable adverse effect. If used, then the effect on pain must be monitored. If opioids are ineffective then they should be discontinued.

\section{Competing interests None.}

Provenance and peer review Commissioned; internally peer reviewed.

To cite Wiffen P. Eur J Hosp Pharm 2013;20:1.

Eur J Hosp Pharm 2013;20:1.

doi:10.1136/ejhpharm-2012-000267

\section{REFERENCES}

1 International Association for the Study of Pain. http://www.iasp-pain.org (accessed 7 Dec 2012)

2 Moore RA, Derry S, McQuay HJ, et al. Single dose oral analgesics for acute postoperative pain in adults. Cochrane Database Syst Rev 2011;(9):CD008659. 